\title{
ANÁLISE DE COLIFORMES EM PROCESSO DE BIODIGESTÃo ANAERÓBIA DE ÁGUAS RESIDUÁRIAS HUMANAS
}

\author{
ANALYSIS OF COLIFORMS IN ANAEROBIC DIGESTION PROCESS OF \\ HUMAN WASTEWATER
}

\author{
P. M. P. BRANCO ${ }^{1 *}$, R. G. S. NOGUEIRA ${ }^{2}$, L. M. S. FERREIRA ${ }^{1}$, F. A. BORGES ${ }^{3}$, J. LUCAS JÚNIOR ${ }^{1}$
}

\section{RESUMO}

O transtorno gerado pelos resíduos provenientes das redes de esgoto doméstico e da produção animal é um grande problema no contexto atual. Aliar sistemas eficientes que possam garantir o desenvolvimento e ainda preservar o meio tem sido o propósito das ações de pesquisadores para garantir a sustentabilidade ambiental. O objetivo foi avaliar a eficiência do sistema de biodigestão anaeróbia de águas residuárias humanas, no processo redução dos micro-organismos indicadores de contaminação fecal (coliformes totais e coliformes termotolerantes), visando a utilização do efluente como adubo de solo para pastagem. As amostras foram colhidas semanalmente durante 4 meses, totalizando 108 amostras de afluente do biodigestor tubular e lagoa de estabilização. As análises foram realizadas por meio da técnica de tubos múltiplos (APHA; AWWA; WEF, 2005), no Laboratório de Biomassa I do Departamento de Engenharia Rural pertencentes à FCAV/UNESP, Câmpus de Jaboticabal. Ao analisar o sistema de biodigestão anaeróbia, desde a entrada do esgoto (afluente) até o ponto final, após o tratamento (lagoa), observou-se eficiência de remoção de $98,75 \%$ para coliformes totais (CTot) e para os coliformes termotolerantes (CTer) de 99,26\%. Portanto, os pontos de coleta no afluente e lagoa diferiram estatisticamente pelo teste de Tukey ao nível de 5\% de probabilidade. Embora o sistema de tratamento tenha atingido boa eficiência de remoção, os parâmetros obtidos para CTot $\left(1,88 \mathrm{E}+04 \mathrm{NMP} \mathrm{mL}^{-1}\right)$, e para CTer $\left(1,48 \mathrm{E}+04 \mathrm{NMP}_{\mathrm{mL}}^{-1}\right)$ não atingiram os padrões pré estabelecidos na Resolução CONAMA 357 (BRASIL, 2005), os quais não poderão ser utilizadas para irrigação de forrageiras.

PALAVRAS-CHAVE: ESGOTO SANITÁRIO. FERTILIZANTE. MICRO-ORGANISMOS INDICADORES. SUSTENTABILIDADE AMBIENTAL.

AGRADECIMENTOS: Cnpq e Copercana

ÁREA TEMÁTICA: Saúde Pública

\footnotetext{
${ }^{1}$ Faculdade de Ciências Agrárias e Veterinárias da Universidade Estadual Paulista (UNESP) - Câmpus de Jaboticabal * paulapilotto@hotmail.com

${ }^{2}$ Faculdade de Zootecnia e Engenharia de Alimentos da Universidade de São Paulo (USP) - Câmpus de Pirassununga ${ }^{3}$ Faculdade de Medicina Veterinária e Zootecnia da Universidade Federal do Mato Grosso do Sul (UFMS) - Câmpus de Campo Grande
} 